\title{
DETERMINAÇÃO DA MISTURA ÓTIMA PARA COMPOSTAGEM DE DEJETOS SUÍNOS UTILIZANDO MARAVALHA DE MADEIRA
}

\author{
Felipe Jurça Fernandes, Tecnólogo em Gestão Ambiental; lipejurca@gmail.com \\ MSc. Felipe Moreton Chohfi, Instituto Federal do Sul de Minas Gerais - Campus Inconfidentes; \\ fmchohfi@yahoo.com.br
}

\section{RESUMO}

O trabalho foi realizado na Fazenda Experimental do Instituto Federal do Sul de Minas Gerais, Campi Inconfidentes e teve como objetivo determinar uma formulação de mistura ótima para compostagem de resíduos suínos utilizando-se maravalha de madeira como propiciador/suporte da compostagem. Neste sentido, experimentos foram realizados em um tambor compostor rotor com capacidade para 200 litros (cerca de $120 \mathrm{~kg}$ ) que permitiu o monitoramento dos parâmetros da compostagem em escala piloto/laboratorial. Foram analisados parâmetros de temperatura, umidade e materiais voláteis que permitiram monitorar o desenvolvimento temporal do processo de compostagem. Os resultados obtidos mostram a dificuldade de obter condições favoráveis para o desenvolvimento do processo devido à baixa relação $\mathrm{C} / \mathrm{N}$ e umidade elevada dos dejetos suínos e aos problemas ocorrentes com a coleta e armazenamento dos dejetos nas instalações da suinocultura do Instituto Federal do Sul de Minas Gerais, Campi Inconfidentes. O bom andamento de um processo de compostagem resulta em produto final de maior valor agregado, pois contém maior teor de nutrientes e reduzido teor de carga orgânica ao se comparar com o dejeto in natura.

\section{INTRODUÇÃO}

A aplicação de matéria orgânica no solo exerce efeitos claramente benéficos sobre suas propriedades se estiverem presentes em quantidades apropriadas, contribuindo assim para o crescimento e desenvolvimento das plantas. A matéria orgânica tem influência direta sobre as propriedades físicas, químicas e biológicas do solo, influenciando positivamente no aumento da produção agrícola. Os resíduos gerados pela produção agropecuária, assim como estercos animais in natura e restos culturais podem ser chamados de Fertilizantes Orgânicos

Simples (KIEHL, 1985), mas é recomendada sempre a atenção aos cuidados que devem ser despendidos no seu tratamento e utilização, uma vez que estes, não devem ser dispostos no ambiente sem o devido tratamento, pois assim, o que acarretaria em contaminação e possíveis prejuízos futuros.

O Brasil é o único país da América Latina incluído na lista dos 10 maiores produtores mundiais de carne suína, sendo responsável por 7,5\% das exportações mundiais. O rebanho suíno nacional estimado para 2008 foi de 38.164 .000 cabeças, concentrando na região Sul cerca de 20.291.000 cabeças (53,17\% do rebanho nacional) (MIELE, 2007).

Até a década de 70 os resíduos da criação de suínos não representavam problemas para a população e para o meio ambiente, pois a concentração de animais era ainda pequena; porém, o desenvolvimento da suinocultura intensiva aumentou a produção de dejetos, que na maioria das vezes são lançados ao solo, tornando-se grande fonte de poluição de mananciais de água (OLIVEIRA, 2002; OLIVEIRA, 2004).

De acordo com KONZEN (2000) os dejetos de suínos podem se constituir em fertilizantes eficientes na produção de grãos e de forragens, desde que adequadamente dosados e estabilizados 
(temperatura em torno de $30^{\circ} \mathrm{C}$ e umidade de $45 \%$ ) e antes de sua utilização. Quando dispostos inadequadamente no meio ambiente, os resíduos sem tratamento podem trazer problemas de contaminação de mananciais, reservatórios de água e solos. Além da poluição hídrica e do solo, deve-se também considerar a emissão de gases gerados pelos diferentes sistemas de tratamento adotados (KERMARREC, 1999; ZAHN et al., 2001; OLIVEIRA et al., 2000; OLIVEIRA et al., 2003a).

Muitos desses gases são tóxicos, além de produzirem odores desagradáveis, que são sentidos a grandes distâncias, além dos limites da fonte emissora. Adaptações evitando a emissão de odores exigem altos investimentos. A compostagem é tida como alternativa de baixo custo e eficiente na diminuição da dispersão de mau cheiro (MEDRI, 1997; OLIVEIRA, 2004.; citados por OLIVEIRA, 2006).

O desenvolvimento deste trabalho é uma iniciativa para o desenvolvimento de projetos para tratamento de resíduos da produção agropecuária e caminha, com as propriedades rurais, rumo a uma economia ecologicamente sustentável.

Assim, o objetivo deste trabalho foi o de testar diferentes formulações para obtenção de composto orgânico de esterco suíno, utilizando a maravalha de madeira como propiciador/suporte do processo de compostagem, a fim de utilizar o material obtido como fertilizante.

\section{MATERIAL E MÉTODOS}

O estudo foi realizado no município de Inconfidentes, Sul do Estado de Minas Gerais, nas dependências da Fazenda Experimental do Instituto Federal do Sul de Minas Gerais.

Foram realizados testes pára compostagem de quatro misturas com diferentes composições. O Quadro 1 a seguir mostra asa composições das misturas experimentadas.
QUADRO 1: Misturas para compostagem

\begin{tabular}{|c|c|}
\hline Misturas & Ingredientes \\
\hline $\mathbf{0 1}$ & $\begin{array}{c}\text { Esterco suíno fresco }(40 \mathrm{~kg})+\text { cana-de- } \\
\text { açúcar picada }(20 \mathrm{~kg})+\text { palha de café } \\
(56 \mathrm{~kg})\end{array}$ \\
\hline $\mathbf{0 2}$ & $\begin{array}{c}\text { Esterco suíno fresco }(60 \mathrm{~kg})+\text { palha de } \\
\text { café }(20 \mathrm{~kg})+\text { maravalha de madeira } \\
(10 \mathrm{~kg})\end{array}$ \\
\hline $\mathbf{0 3}$ & $\begin{array}{c}\text { Esterco suíno fresco }(60 \mathrm{~kg})+\text { maravalha } \\
\text { de madeira }(20 \mathrm{~kg})\end{array}$ \\
\hline $\mathbf{0 4}$ & $\begin{array}{c}\text { Esterco suíno fresco }(10 \mathrm{~kg})+\text { maravalha } \\
\text { de madeira }(05 \mathrm{~kg})+\mathrm{cama} \text { equina } \\
(56 \mathrm{~kg})\end{array}$ \\
\hline
\end{tabular}

Fonte: FERNANDES, 2009.

Para realização das misturas foi utilizada a tecnologia piloto chamada de "compostos rotor", composto por um tambor de 200 litros, com capacidade para cerca de 120 $\mathrm{kg}$ de material, montado e apoiado sobre um suporte de metal com roldanas, a fim de permitir sua rotatividade para mistura e aeração dos materiais. $\mathrm{O}$ tambor é transpassado por um tubo de PVC de $07 \mathrm{~cm}$ de diâmetros e pequenos furos em toa sua extensão, que permitem a entrada de ar no interior da mistura, além de dar vazão ao chorume produzido (Figura 1).

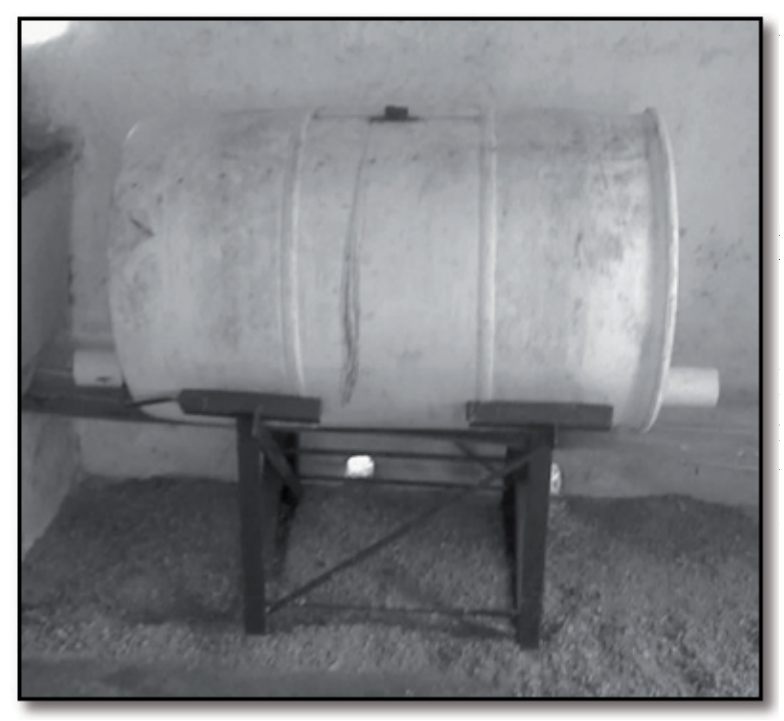

FIGURA 1 - Compostor rotor (FERNANDES, 2009). 
Os materiais foram pesados em balança mecânica localizada no setor de suinocultura da FEIFSMG (Fazenda Experimental do Instituto Federal do Sul de Minas Gerais). As misturas chamadas 01 e 02 foram inseridas no compostor e este foi deixado ao ar livre, contando apenas com uma proteção plástica contra chuva (Figura 2).

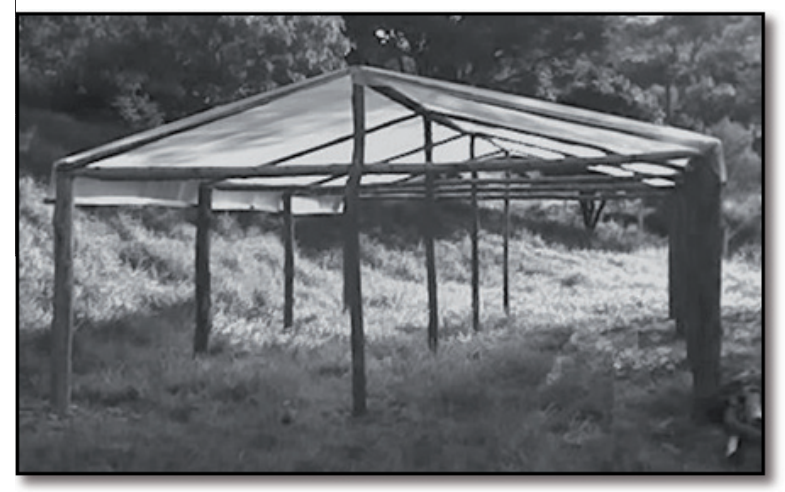

FIGURA 2 - Cobertura de instalação das misturas 01 e 02 .

As misturas chamadas 03 e 04 foram inseridas no compostor e este foi armazenado no interior do antigo galpão de criação de frangos de corte da FEIFSMG.

As misturas 01, 02 e 03 tiveram suas formulações definidas de forma empírica, de forma a definir proporções que regulassem umidade e fornecessem uma relação $\mathrm{C} / \mathrm{N}$ adequada (de cerca de 30/1). Já a mistura 04 teve sua formulação definida com base nos resultados obtidos com a utilização das equações 01 e 02 propostas por TRAUTMANN \& KRASNY (1997).

EQUAÇÃO 1. Determinação da quantidade, em massa, de propiciados/suporte será necessária para tratar, em termos de umidade, uma massa prédefinida de dejetos.

$$
\boldsymbol{E Q . 0 1} \rightarrow W_{2}=\frac{\left(W_{1} \times G\right)-\left(W_{1} \times M_{1}\right)}{M_{2}-G}
$$

Onde: $\mathrm{W}_{2}=$ massa $(\mathrm{kg})$ do meu propiciador a ser utilizado para tratar o meu dejeto; $\mathrm{W}_{1}=$ massa $(\mathrm{kg})$ do dejeto a ser tratado; $\mathrm{G}=$ umidade desejada; $M_{1}=$ Umidade $(\%)$ do meu dejeto a ser tratado; $\mathrm{M}_{2}=$ Umidade $(\%)$ do meu propiciador.

EQUAÇÃO 2. Determinação da quantidade, em massa, do propiciador/suporte necessária para balancear uma massa pré-definida de dejetos em termos de relação $\mathrm{C} / \mathrm{N}$.

$$
E Q .02 \rightarrow W_{2}=\frac{\left(W_{1} \times N_{1}\right) x\left(R-\left(\frac{C_{1}}{N_{1}}\right)\right) x\left(100-M_{1}\right)}{N_{2} x\left(\left(\frac{C_{2}}{N_{2}}\right)-R\right) x\left(100-M_{2}\right)}
$$

Onde: $\mathrm{W}_{2}=$ Massa $(\mathrm{kg})$ do meu propiciador/ suporte a ser utilizado para balancear uma massa desejada de dejeto em termos de relação $\mathrm{C} / \mathrm{N} ; \mathrm{W}_{1}=$ Massa total conhecida do meu dejeto a ser tratado; $\mathrm{N}_{1}=$ Conteúdo (\%) de nitrogênio do meu dejeto; $\mathrm{R}=$ Relação $\mathrm{C} / \mathrm{N}$ necessária à compostagem; $\mathrm{C}_{1}=$ Conteúdo de carbono $(\%)$ de meu dejeto; $M_{1}=$ Umidade $(\%)$ do meu dejeto a ser tratado; $\mathrm{N}_{2}=$ Conteúdo (\%) de nitrogênio do propiciador/suporte; $\mathrm{C}_{2}=$ Conteúdo de carbono (\%) do meu propiciador/suporte; $\mathrm{M}_{2}=$ Umidade (\%) do meu propiciador/suporte;

No decorrer dos experimentos a temperatura foi aferida diariamente, utilizandose um termômetro digital portátil, sensor tipo espeto, modelo RÜCKEN RTDP-700-E. $\mathrm{O}$ registro das temperaturas foi realizado manualmente em planilhas com os valores da média aritmética simples dos valores de três pontos aferidos no interior da mistura. Para confecção dos gráficos representativos das curvas de temperatura foi utilizado o software Microsoft Excel - Pack Office 2007.

As misturas também foram testadas para obtenção de valores de umidade e materiais voláteis (mataria orgânica).

Para os testes de umidade foi utilizada a metodologia citada por MOHEE \& CHOHFI (2006), anotando-se o peso da amostra úmida, 
colocando-se a amostra em estufa a $105^{\circ} \mathrm{C}$ por um período de 24 horas e em seguida anotando-se o peso da amostra seca. A diferença percentual de peso entre as pesagens antes e depois da secagem define a porcentagem de umidade da mistura. A estufa utilizada para as análises de umidade foi a estufa localizada no laboratório de irrigação e drenagem da IFSM em Inconfidentes/MG.

Para os testes de materiais voláteis, foi também seguida a metodologia citada pelos mesmos autores, pesando-se e separando-se as amostras em cadinhos que foram levados a um forno (mufla) a $550^{\circ} \mathrm{C}$ por um período de 3 horas. $\mathrm{O}$ material restante após a queima foi novamente pesado. A diferença de peso entre as amostras antes e depois da queima define o percentual de matérias voláteis contidos na mistura, ou seja, o percentual de matéria orgânica da mistura. $\mathrm{O}$ forno utilizado para as análises foi a mufla do laboratório de análise de solos do IFSM.

\section{RESULTADOS E DISCUSSÃO}

\section{Mistura 01}

A Mistura 01 teve sua temperatura monitorada durante 09 dias e não havendo elevação da temperatura a valores favoráveis ao desenvolvimento do processo de compostagem a aferição da temperatura foi interrompida e a mistura foi considerada inadequada para realização de compostagem a fim de obter composto orgânico para fins de uso como fertilizante.

A umidade de 66,18\% encontrada na análise da mistura 01 foi considerada elevada e tomada como causa da não elevação da temperatura da Mistura 01, o que impossibilita o estabelecimento do processo de compostagem, devido ao não estabelecimento de atividade microbiana termófila. A palha-de-café utilizada foi insuficiente para absorver a umidade em excesso no material da mistura.

A Figura 03 ilustra a curva de temperatura obtida por meio do processamento dos dados de temperatura da Mistura 01.

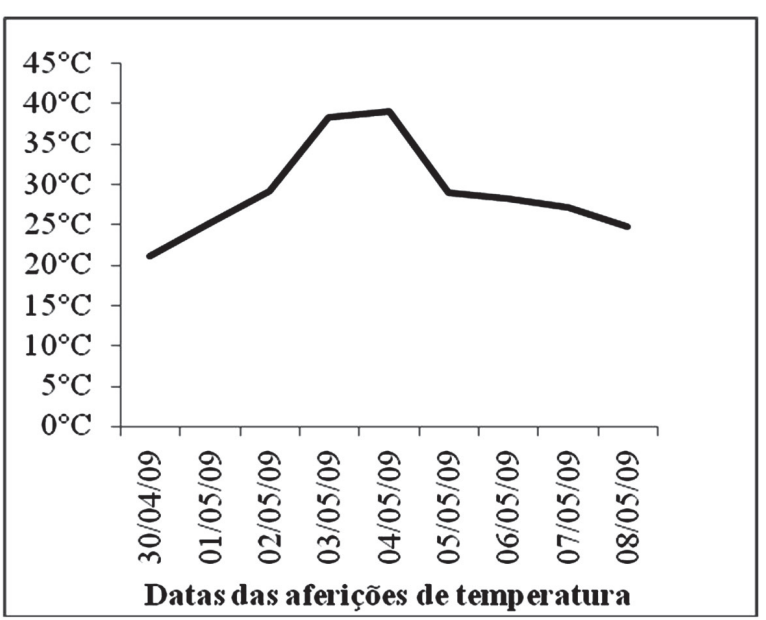

FIGURA 03 - Curva representativa das temperaturas atingidas durante o processo desenvolvido pela Mistura 01 .

A alta umidade deve-se à composição dos dejetos suínos disponíveis no setor de suinocultura da FEIFSM. Não existe um processo adequado de separação de resíduos sólidos e líquidos, ocorrendo ainda problemas com o aumento da umidade natural devido à entrada de águas pluviais nas caixas de armazenamento dos dejetos. Pode-se observar ainda, dentro dos galpões de criação dos animais, problemas com utilização de água em excesso na lavagem das instalações e desperdício de água nos bebedouros dos animais. Toda essa água tem o mesmo destino dos dejetos, o que aumenta a umidade dos mesmos.

\section{Mistura 02}

A Mistura 02 teve sua temperatura monitorada durante 14 dias e teve o mesmo resultado apresentado pela Mistura 01 .

O mesmo fator determinante de não absorção de umidade, a quantidade de palha-decafé, na Mistura 01 agiu na Mistura 02, por isso, aos 08 dias após o enchimento do compostor com a mistura foi inserida uma quantidade de 10 $\mathrm{kg}$ de maravalha de madeira a fim de melhorar o processo de absorção da umidade em excesso e fornecer uma fonte de carbono maior para o processo. A inserção da maravalha não surtiu o efeito desejado, não impedindo a continuação 
da diminuição da temperatura. Considerou-se a quantidade de maravalha insuficiente para o fim desejado.

A Figura 04 a seguir mostra a curva representativa das temperaturas atingidas pela Mistura 02.

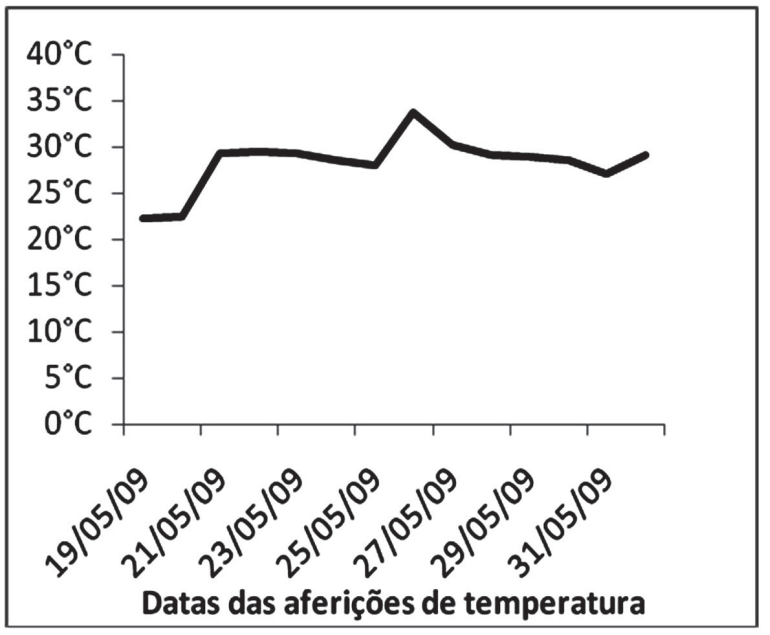

FIGURA 04 - Curva representativa das temperaturas atingidas durante o processo desenvolvido pela Mistura 02.

A temperatura para desenvolvimento adequado da atividade microbiana e consequentemente do processo de compostagem deve atingir valores por volta dos 65 a $70^{\circ} \mathrm{C}$ nos primeiros sete dias, caracterizando a fase termofílica da compostagem, porém em nenhuma das misturas testadas a temperatura se elevou. A causa considerada para tanto foi a umidade elevada do material da mistura.

\section{Mistura 03}

A Mistura 03 teve sua temperatura monitorada durante apenas 07 dias e não havendo elevação da temperatura a valores favoráveis ao desenvolvimento do processo de compostagem a aferição da temperatura foi interrompida e a mistura foi considerada inadequada para realização de compostagem a fim de obter composto orgânico para fins de uso como fertilizante.
As temperaturas da Mistura 03 não atingiram valores maiores que $27^{\circ} \mathrm{C}$, sendo a Mistura 03 considerada a menos eficiente para o estabelecimento de processos de compostagem.

A Mistura 03 apresentou o maior índice de umidade $(72,20 \%)$ dentre as misturas testadas. Isso mostra o aumento na alteração das propriedades dos dejetos oriundos da granja suína da FEIFSM pelo manejo da criação. Esperava-se que a umidade em excesso fosse absorvida pela quantidade de maravalha de madeira inserida na mistura. Visto que na Mistura 03 a palha de café foi totalmente substituída pela maravalha de madeira, a quantidade de maravalha foi considerada insuficiente no objetivo de redução de umidade.

A alta umidade e a baixa temperatura não propiciaram condições para o estabelecimento de atividade microbiana e de compostagem.

A Figura 05 a seguir mostra a curva das temperaturas atingidas pela Mistura 03 .

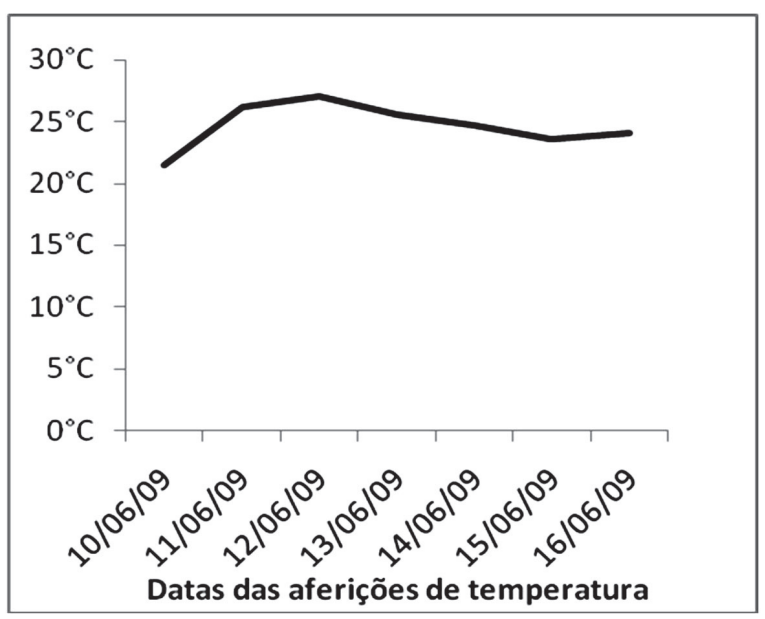

FIGURA 05 - Curva representativa das temperaturas atingidas durante $\mathrm{o}$ processo desenvolvido pela Mistura 03 .

É certo que o maior problema encontrado é a não uniformidade nas características, principalmente na umidade dos dejetos disponíveis para compostagem na suinocultura da FEIFSM. A quantidade de palha foi insuficiente, pois a umidade do material estava 
ainda maior do que a do material utilizado nas Misturas 01 e 02.

\section{Mistura 04}

Durante 10 dias os dados de temperatura da Mistura 04 foram monitorados.

Nos primeiros dois dias os valores de temperatura da mistura atingiram o esperado, chegando a valores próximos dos $40^{\circ} \mathrm{C}$, porém, esse valor não se manteve. A causa da queda da temperatura foi considerada a quantidade baixa de maravalha de madeira utilizada, mesmo esta tendo sido definida por meio dos cálculos das equações propostas por TRAUTMANN \& KRASNY (1997). Visto a queda e não re-aumento da temperatura a aferição de temperaturas da Mistura 04 foi interrompida 10 dias após o enchimento do compostor.

Considerou-se como fator determinante do não estabelecimento do processo o mesmo das três misturas anteriores, ou seja, a umidade elevada dos dejetos da suinocultura da FEIFSMG.

A Figura 06 a seguir mostra a curva representativa dos valores de temperatura atingidos pela Mistura 04 .

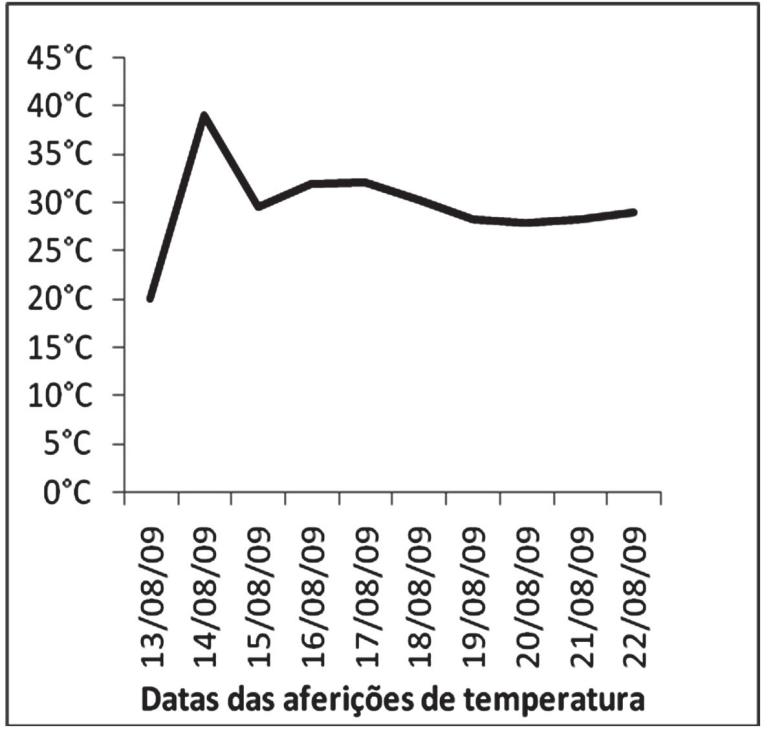

FIGURA 06. - Curva representativa das temperaturas atingidas durante o processo desenvolvido pela Mistura 04.
O cálculo para definição da receita permitiu a adequação dos fatores relação $\mathrm{C} / \mathrm{N}$ e umidade à realização de compostagem, porém alguns cuidados deveriam ser tomados com relação à inserção do material no compostor. Sugere-se, para o desenvolvimento de trabalhos futuros, a inserção seriada de dejetos na mistura de maravalha de madeira com cama equina para experimentos futuros. A inserção dos dejetos aos poucos pode permitir a absorção mais adequada de umidade pela maravalha de madeira favorecendo o estabelecimento do processo de compostagem.

\section{Controle de Odor}

Constatou-se que o maior problema enfrentado pelo IFSMG com relação ao setor de suinocultura é o aparecimento de odores desagradáveis oriundos da decomposição anaeróbia dos dejetos nas lagoas de tratamento e ainda oriundos do interior das instalações de criação.

O IFSMG enfrenta problemas com a comunidade local que apresenta periodicamente reclamações formais com relação à presença de mau cheiro no município, oriundo da criação de suínos do Instituto.

As quatro Misturas, ainda que não desenvolvessem o processo de compostagem de maneira satisfatória, apresentaram-se eficientes no controle do odor desagradável dos dejetos.

O simples fato de permitir o mínimo de aeração e diminuir a umidade do material por si só já diminui a liberação de mau cheiro. A condução adequada do manejo das lagoas de tratamento e da destinação dos dejetos, além, é claro, da manutenção das características naturais dos dejetos, com relação á umidade é a melhor maneira de mitigar os problemas relacionados ao odor desagradável que acomete a comunidade de Inconfidentes.

Devem ser desenvolvidos trabalhos de forma a destinar corretamente os resíduos de todos os setores da produção agropecuária. 
O desenvolvimento de projetos de pesquisa na área de tratamento de resíduos é uma necessidade mundial vista a atual situação e alcance das preocupações com o meio ambiente. Um ambiente saudável pode ser alcançado com o trabalho em equipe e com a disseminação de técnicas e idéias inovadoras para possibilitar a proteção e manutenção da disponibilidade dos recursos naturais necessários para o desenvolvimento de uma vida saudável e em consonância com o meio ambiente de todos os seres vivos.

\section{CONCLUSÕES}

Não foi, dentre as misturas testadas, encontrada a formulação ótima para o desenvolvimento do processo de compostagem satisfatoriamente.

Sugere-se a incorporação seriada de dejetos à maravalha de madeira como forma de absorver umidade e obter o desenvolvimento aeróbio de micro-organismos necessários ao desenvolvimento do processo.

Ainda que o processo de compostagem objetivado não tenha sido atingido, todas as misturas se mostraram eficientes no controle de maus odores relacionados aos resíduos da suinocultura, sendo este um dos maiores problemas enfrentado pelas instalações do Instituto.

Os dados desse trabalho devem ser utilizados como parâmetros de estudo para a implantação futura de uma usina de compostagem, em larga e média escala, não só nos domínios do IFSM, mas em qualquer propriedade rural.

\section{REFERÊNCIAS}

KERMARREC, C. Bilan et transformations de l'azote en élevage intensif de porcs sur litière. 1999. 272p. Thèse (Docteur). 1' ENSA de Rennes, France. de suínos. Concórdia - EMBRAPA-CNPSA. (Circular Técnica, 6), 32p. 1983.

MIELE, M. Levantamento sistemático da produção e abate de suíno: 2006 e 2007. Embrapa Suínos e Aves. Concórdia. Santa Catarina. $1^{\text {a }}$ Ed. 2007. 29 p.

MOHEE, R.; CHOHFI, F. M. Composting of filter cake in view of organic fertilizer usage. Sugar Cane International. vol. 24. n. 2. p. 22-25. 2006.

OLIVEIRA, P. A. V.; KERMARREC, C.; ROBIN, P. Balanço de nitrogênio e fósforo em sistema de produção de suínos sobre cama de maravalha. In: CONGRESSO MERCOSUR DE PRODUCCIÓN PORCINA, 2000, Buenos Aires. Memória. Buenos Aires: [s.n.], 2000. p.SP7.

OLIVEIRA, P. A. V.; NUNES, M. L. A.; KUNZ, A.; HIGARASHI, M. M.; SCHIERHOLT NETO, G. F. Utilização de compostagem para o tratamento dos dejetos de suínos. In: CONGRESSO BRASILEIRO DE VETERINARIOS ESPECIALISTAS EM SUÍNOS. Goiânia, GO. Anais... Concórdia: Embrapa Suínos e Aves, 2003a. p.433-434.

OLIVEIRA, P. A. V. Programas eficientes de controle de dejetos na suinocultura. In: CONGRESSO LATINO AMERICANO DE SUINOCULTURA, 1., 2002, Foz do Iguaçu. Anais... Concórdia: Embrapa Suínos e Aves, 2002. p.143-15.

OLIVEIRA, P.A. V. de.; CASTILHO JUNIOR, A. B.; NUNES, M. L. A.; HIGARASHI, M. M. Compostagem usada para o tratamento dos dejetos de suínos. In: CONGRESSO LATINO AMERICANO DE SUINOCULTURA, 2.; CONGRESSO DE SUINOCULTURA DO MERCOSUL, 4., 2004, Foz do Iguaçu. Anais... Campinas: Editora Animal/World, 2004. p.522-523. 
OLIVEIRA, P. A. V. de.; HIGARASHI, M. M.; Unidade de compostagem para o tratamento de dejetos suínos. Concórdia: Embrapa Suínos e Aves, 2006. 39 p.

TRAUTMANN, N. M.; KRASNY, M. E. Composting in the classroom - Scientific inquiry for high school students. Ed. Cornell
University. 1997. 126 p.

ZAHN, J. A.; HATTFIELD, J. L.; LAIRD, D. A.; HART, T. T.; DO, Y. S.; DISPIRITO, A. A. Functional classification of swine manure management systems based on effluent and gas emission characteristics. Journal Environment Quality, v.30, p.635-647, 2001. 